\title{
A Numerical Study of Smoke Movement along an Inclined Coal Conveyor
}

\author{
A.R. GREEN \\ Department of Safety Science \\ University of New South Wales \\ Australia \\ D.F. FLETCHER \\ Department of Chemical Engineering \\ University of Sydney \\ Australia
}

\begin{abstract}
Conveyor belt systems used in underground mines have the potential to give rise to severe fires unless they are made from a suitable material. Statistical data on such fires show that the most significant risk is from collapsed idler rollers. We have performed a study to assess the characteristics of such fires and to determine their influence on personnel working within an underground system. Cone Calorimeter testing was carried out to determine the combustion properties of typical belt materials. From this information, we used Computational Fluid Dynamics (CFD) to simulate the spread of heat and smoke through the tunnel. These simulations showed that the fire results in a strong plume which causes smoke and hot gases to form a stratified layer along the roof of the tunnel and to curl back down in the region of the fire because of the interaction of the plume with the roof. The consequences of the fire on personnel working in the region of the conveyor are considered.
\end{abstract}

\section{KEYWORDS}

Fire Modelling, Smoke, Mine Fires 


\section{INTRODUCTION}

Conveyor belt systems underground have the potential for severe fires unless suitable materials are used in their construction. Consequently, conveyor belts are required to meet fire resistant standards in Australia [1]. The cost to the industry is considerable, as introduction of fire resistance to the conveyor impacts on other desirable properties of the belt, such as abrasion resistance. The question must be asked as to whether alternative control strategies can lead to the same or better levels of safety, as reliance solely on the fire resistance of the belt material.

This paper explores the effect of different conveyor materials on likely fire spread and smoke production for a belt in an inclined roadway. After describing the background to this study, results from Cone Calorimeter tests of belt material are presented. Next we describe the mathematical model used to study movement of heat and smoke, and then we present the results from a number of simulations of belt fires in the conveyor geometry. Finally, we draw some conclusions about such fires and the utility of the approach described here to access fire hazards.

\section{BACKGROUND}

The main fuel mass in the conveyor structure is contained within the belt. Different grades of conveyor material have different fire properties. To initiate a conveyor fire a source of ignition must be present. Historical data [2-4] from the hard coal industry in NSW, shows that while the number of fires underground has been declining, the number of conveyor fires has remained relatively static (see Figure 1).

The most common scenario is that of an idler bearing failure, which can occur over the entire length of the conveyor system. This scenario has been chosen as the basis of a Computational Fluid Dynamics (CFD) study to predict the threat to life safety from a growing fire in an inclined roadway. The threat to life safety is regarded as a combination of the build up of heat, smoke and reduced visibility. Two different neoprene conveyor belt materials (a fire resistant, grade $S$ and an

FIGURE 1 Underground Coal Mine Fires in NSW, 1963-1995

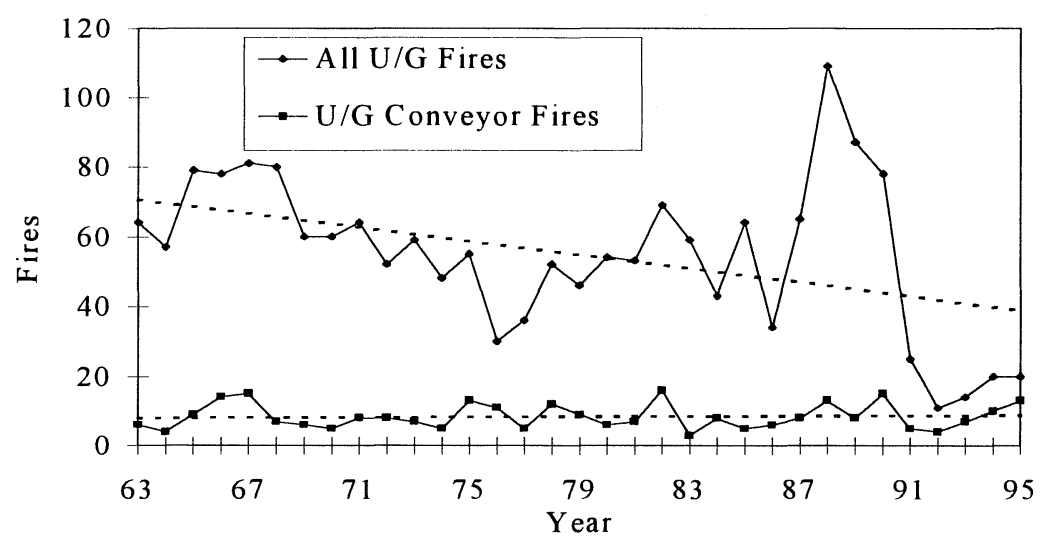


abrasion resistance, grade A, belt) were analysed by Cone Calorimetry [5] to obtain typical fire properties.

\section{Cone Calorimetry of Conveyor Belt Materials}

The Cone Calorimeter uses a cone shaped electrical heater to provide a constant heat flux over a $100 \mathrm{~mm}$ by $100 \mathrm{~mm}$ sample held in a sample holder on a weighing platform. The edges of the sample are protected by a ceramic clay that has virtually no shrinkage or mass loss from water evaporation under the test conditions. The principle behind the test method relies on the fact that the majority of fuels release the same amount of heat, when measured on the basis of mass of oxygen consumed [6]. The value used here is $13.1 \mathrm{MJ} / \mathrm{kg}$ of oxygen consumed. Tests were conducted on two neoprene conveyor belt samples, identified as $\mathrm{A}$ and $\mathrm{S}$, in the Cone Calorimeter to establish their fire properties. The tests were conducted to ASTM 1354, in which each sample was tested in a horizontal orientation and subjected to constant and uniform heat flux of 25,35 and $50 \mathrm{kWm}^{-2}$. The test results are presented in Table 1.

Both belts exhibited considerable swelling during testing. Belt $\mathrm{A}$, in particular, exploded during tests at the higher heat fluxes. As a consequence, data from both the 35 and $50 \mathrm{kWm}^{-2}$ incident heat flux tests were treated with caution for this particular material. The test at a $25 \mathrm{kWm}^{-2}$ incident heat flux did not show the same behaviour. The sample of belt $\mathrm{S}$ did not produce sustained burning at an incident heat flux of $25 \mathrm{kWm}^{-2}$ although transitory burning was observed throughout the test. Alternate ignition, self-extinguishment and transitory flaming occurred at the higher heat fluxes with the $\mathrm{S}$ grade belt. The grade $\mathrm{A}$ belt burnt vigorously once flaming was established.

One of the objectives of the study is to develop simulations of a fire to determine their impact on life safety. The results should be a definition of untenable conditions within the roadway and the time taken to reach those untenable conditions. The criterion often used in fire studies is the arrival at head height $(1.8 \mathrm{~m})$ of untenable conditions [7]. These conditions include the impact of temperature, smoke and toxic materials. The main scenario chosen for modelling is based on that of a collapsed or stalled idler which ignites the belt material. The belt fire is assumed to grow over time, releasing smoke, heat and toxic gases into the roadway. The rate at which this occurs depends on the fire properties of the belt materials. The values measured using cone calorimetry are discussed below.

In ventilated mine roadway fires of this nature, studies have shown $[8,9]$ that downwind of the fire, the hot plume forms a stratified layer in the tunnel. This layer gradually cools and mixes completely as it does so. This, however, will be some distance (greater than $50 \mathrm{~m}$ ) from the fire. The degree of mixing will be suppressed, compared with a horizontal tunnel, by the incline of the roadway due to buoyancy being partially aligned with the exhaust flow. Thus the arrival of untenable conditions at head height, downwind of the fire is difficult to quantify without a detailed study of the heat soak characteristics of the tunnel.

Upwind of the fire, smoke can backup against the ventilation flow. The distance it backs up is a function of the ventilation rate and fire size. CFD studies $[8,9]$ of this aspect of fire plume flow give reasonable agreement with experimental data. The smoke is mainly in the buoyant layer separated by a distinct interface from the fresh ventilation air below it. Near the extremity of the buoyant layer, which has cooled significantly, there is a tendency for smoke to lose its buoyancy and mix with the incoming air. As a result, the air below the plume layer is contaminated with smoke. The 
amount of smoke below the plume depends on the density of the smoke in the plume and the rate of cooling. In the pool fire experiments $[8,9]$ observation of the air below the plume showed that the visibility was not impaired by more than $20 \%$. Conveyor fires produce much thicker and more toxic smoke and it would be expected that conditions under the plume would be worse than in the above tests.

In order to best approximate conditions of a growing fire in a roadway it has been assumed that the first 10 minutes are critical for escape of personnel in the roadway. Consequently a design fire was used in the modelling based on the Cone calorimetry data and experience from previous experiments on flame spread rates $[10,11]$. The peak values for heat release rate within this time for each material are shown in Table 1 for the three different incident heat fluxes. The values of the other variables shown correspond to the same time as the peak heat release rate and generally correspond to maxima or minima in their respective time lines. The peak mass loss rate and flux were measured directly. The peak heat release rate (HRR) and flux (HHF) were derived from oxygen depletion measurements and the flowrate through the measurement duct.

The soot volume fraction is derived from the minimum transmission coefficient of a laser beam across the Cone Calorimeter outlet during the first 10 minutes of the experiment [12]. The assumption made is that the soot produced is sufficiently small to cause Rayleigh, rather than Mie, scattering of the laser light. The soot mass fraction was calculated from the volume fraction, the volume flowrate and the mass loss rate of the sample. Carbon monoxide yield per mass of material burned was calculated from the carbon monoxide volume fraction, the volume flowrate and the mass loss rate of the sample.

The design fire used in the modelling is based on fire growth that is quadratic with time. Based on previous experience of fire growth, conveyor fires reach an energy output of $0.5 \mathrm{MW}$ over a period of 5-10 minutes. The peak heat release flux is used to calculate the area for a $0.5 \mathrm{MW}$ fire. This area, shown in Table 1, is then used in the simulations, in which a fire grows from zero to the peak heat release of $0.5 \mathrm{MW}$ as a $\mathrm{t}^{2}$ fire. The mass loss, the soot mass fraction, and carbon monoxide and carbon dioxide yields are simple ratios of the heat release rate based on the data given in Table 1.

\section{Computational Study of Smoke Movement}

Computations were made to study the spread of smoke in the conveyor tunnel using the Computational Fluid Dynamics (CFD) package CFX4 [13]. This package has been used extensively to study smoke spread in situations as diverse as the King's Cross underground fire [14], in aircraft hangers [15], on offshore oil platforms [16] and in tunnels [17]. It has recently undergone extensive validation against hydrocarbon pool fire data [18]. The model is based on the solution of conservation equations for mass, momentum and energy using a finite volume method.

\section{The Geometry}

Initially we considered a $20 \mathrm{~m}$ long section of tunnel in the calculations, using a relatively fine grid for the calculations to provide a good picture of the smoke behaviour in the vicinity of the fire. (This limited length was used to reduce the computation time which was, in any case, many hours on a 


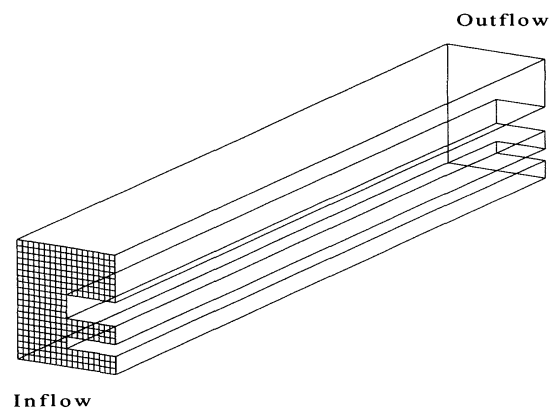

DEC/Alpha 3000.) The model geometry and the numerical grid are shown in Figure 2. The tunnel was made $5.4 \mathrm{~m}$ wide and $3 \mathrm{~m}$ high. Computational cells with a width of $0.15 \mathrm{~m}$, a height of $0.15 \mathrm{~m}$ and a length of $0.5 \mathrm{~m}$ were used which are consistent with previous studies. A plane of symmetry was set along the centre of the tunnel, so that the final grid was composed of 14,400 cells. A 5 degree slope was introduced by changing the direction of the gravity vector. This process meant that an orthogonal mesh could be used, which gives faster convergence and more accurate results.

\section{Model Description}

In order to model the situation of interest we solved the following equations:

- Conservation of mass for each of the gases present in the tunnel;

- Conservation of momentum for the gas in the tunnel. The flow was assumed to be turbulent and to be weakly compressible (i.e. the density is a function of only the local gas composition and its temperature);

- Conservation of energy for the gases present in the tunnel. All gases were assumed to be ideal and the soot was assumed to have a constant heat capacity;

- The k- $\varepsilon$ equations, which determine the turbulent kinetic energy and turbulent dissipation rate. This is a standard engineering model of turbulence and contains terms which represent the turbulence generation due to buoyancy. It is widely used in smoke movement and fire applications [19];

- A conservation equation for the mass fraction of soot. This equation was required so that the local density of soot could be obtained throughout the tunnel.

The form for the equations used is given in the User Manual [13] and in standard books on combustion [19]. Note that we did not attempt to represent the combustion process itself. This task is complex and results in very computationally intensive calculations. Instead, the fire was represented as a source of mass (combustion products and soot) and heat. 
In order to perform the calculations in which a fire was present it was necessary to first obtain a converged solution for the steady flow in the absence of a fire. The pre-fire condition was assumed to be a ventilation draft along the tunnel, which was modelled by specifying an inlet velocity of $0.015 \mathrm{~m} / \mathrm{s}$ into the tunnel and a constant pressure at the tunnel exit. The conveyor belt was assumed to be stationary, representing the fact that as soon as a problem is detected the belt is stopped.

The velocity was set to zero and standard log-law wall functions were used to represent the turbulent boundary layers at the walls. Two different heat transfer boundary conditions were tried when a fire was present. In one case the walls were assumed to be adiabatic, so that no heat is lost and in another they were assumed to remain at their initial temperature. Results of scoping calculations showed that the zero flux condition to be the most dangerous in terms of person egress. This is because in the adiabatic case the smoke plume from the fire escaping around the upper belt was much stronger and more smoke was mixed into the air around the conveyor. In the constant temperature case much of the smoke remained between the conveyor belts. Thus we decided to apply the adiabatic boundary conditions in all subsequent calculations, as it is more conservative with regard to the conditions adjacent to the conveyor.

When a fire was present, heat and mass were input into a volume above the belt at the desired location. The volume of the source and the rate of heat and mass input were based on the experimental data. Typically, a $1 \mathrm{MW}$ fire was represented by inputting heat into a region $0.5 \mathrm{~m}$ wide across the belt and $3 \mathrm{~m}$ along the belt. The fire was assumed to grow as a function of time via $\mathrm{a} \mathrm{t}^{2}$ law, with the peak heat release rate being achieved after typically $300 \mathrm{~s}$, and to be located $5 \mathrm{~m}$ into the roadway section being modelled. The surface beneath the fire was thermally insulated, so that the heat input was not simply lost downwards.

The CFD model was then used to calculate a transient solution, with the temperature field and smoke mass fraction being output at a number of specified times. A time step of typically $0.4 \mathrm{~s}$ was used in the calculation and up to 12 iterations per time step were performed in order to reduce the errors in the iteration process to acceptably small values (typically $20 \mathrm{~g}$ for the total mass error in a tunnel containing $500 \mathrm{~kg}$ of gas).

\section{RESULTS FROM THE CFD SIMULATIONS}

Using the data from the Cone Calorimeter tests, the following scenarios were considered:

(i) For the "A" grade belt the peak heat release rate was set to $1.0 \mathrm{MW}$ and the mass loss rate was set to $17.2 \mathrm{~g} / \mathrm{s}$. In addition, the very high yield of smoke from the belt sample translated into a smoke production rate of $38 \%$ of the mass lost. The ramp time for growth of the fire was set to $300 \mathrm{~s}$. The heat and products were input over a region which was $0.9 \mathrm{~m}$ wide, $3 \mathrm{~m}$ along the belt and $0.4 \mathrm{~m}$ high. With this volume representing the fire the maximum temperature was $1100 \mathrm{~K}$ and the maximum soot mass fraction was 0.005 . The corresponding maximum volume fractions of carbon monoxide and carbon dioxide were $1300 \mathrm{ppm}$ and $4.2 \%$, respectively 
For the "S" grade belt the peak heat release rate was reduced to $0.3 \mathrm{MW}$ because of the lower rate of combustion observed in the tests, and the mass release rate of combustion products was similarly reduced to $13.4 \mathrm{~g} / \mathrm{s}$. $31 \%$ of the mass was assumed to form soot The same area for the fire was used but the vertical height over which the heat and mass were input was reduced by a factor of two to account for the smaller size of the fire. The maximum temperature was $650 \mathrm{~K}$, the maximum soot fraction was 0.004 and the maximum volume fractions of carbon monoxide and carbon dioxide were $2500 \mathrm{ppm}$ and $0.8 \%$, respectively

In order to access the consequences of the fire, temperature plots and soot mass fraction plots were produced at times of $120,240,360,480$ and $600 \mathrm{~s}$ at distances along the tunnel of $5 \mathrm{~m}$ (i.e. at the fire) and at $19 \mathrm{~m}$. In order to allow easy comparison between the plots the contour range has been set from 0 to $5 \mathrm{E}-5$ for the soot mass fraction and from $300 \mathrm{~K}$ to $360 \mathrm{~K}$ for the temperature. Although this obscures some detail in the region of the fire it allows the behaviour in the zone of interest to be examined in detail. The soot contours scale linearly with the carbon monoxide and carbon dioxide concentrations although they differ for the different belts, as indicated in Table 1 .

\section{Results for the "A" Grade Belt}

Figure 3 shows the mass fraction of soot at the fire zone at time intervals of $120 \mathrm{~s}, 240 \mathrm{~s}$ and $360 \mathrm{~s}$ from the start of the fire. At $120 \mathrm{~s}$ a strong plume of smoke is seen to be rising around the conveyor and is almost down to the level of the upper conveyor. By $240 \mathrm{~s}$ a person around this region of the tunnel would have to crawl to avoid the smoke, and from $360 \mathrm{~s}$ onwards there is some smoke even at floor level. Examination of the velocity vectors showed that this smoke is driven downwards by a flow of gas generated by the return flow of air down the tunnel wall. This behaviour is typical of that observed in the convection currents generated by fires. The results show that a quasi steadystate is reached after about $360 \mathrm{~s}$ when the fire has reached its maximum size. Figure 4 shows the temperatures at the same location and the same times. Similar features are shown but it is noteworthy that the temperature rise in the region adjacent to the conveyor is small. It should be noted that the current simulations ignore radiative heat transfer to the air, which would be significant in the very sooty atmosphere around the fire, increasing radiation loading on persons in the tunnel.

Figure 5 shows the mass fraction of soot at the exit of the tunnel at the same times from the start of the fire. Note that there is significant transport of soot between the conveyors and in the region above the conveyors. There is, however, very little smoke below about $2 \mathrm{~m}$. Thus a person could readily escape if they were located this far from the fire. The temperature distributions at the exit showed similar features and are not reproduced here to save space. The $5 \mathrm{E}-5$ soot contour corresponds to $12 \mathrm{ppm}$ carbon monoxide and $400 \mathrm{ppm}$ carbon dioxide, respectively.

\section{Results for the "S" Grade Belt}

Similar results to those described above were obtained for the " $S$ " grade belt. In particular, the distribution and density of smoke was very similar in the two cases. In the second case the temperatures were lower and this resulted in a much weaker plume initially. This meant that the smoke took longer to be convected up to the space above the conveyor and consequently the region adjacent to the conveyor stayed free of smoke for about an extra $60 \mathrm{~s}$. The slower development of the plume compared with the " $\mathrm{A}$ " grade belt is evident if the temperature plot at $360 \mathrm{~s}$, shown in 
FIGURE 3 Mass fraction of soot at the fire top - 120s; middle - 240s; bottom - 360s. (Contour range 1.E-5 to 5E-5.)
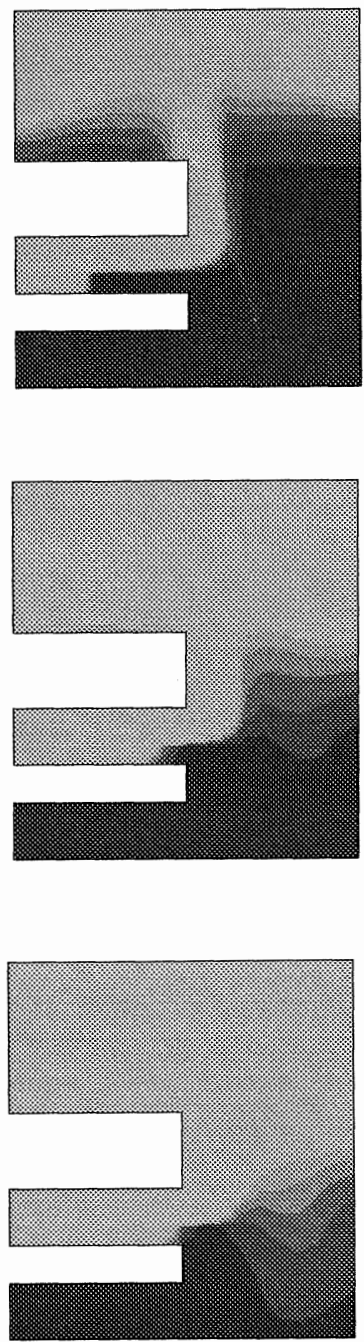

FIGURE 4 Temperature at the fire top - 120s; middle - 240s; bottom - 360s. (Contour range 300 - $360 \mathrm{~K}$.)
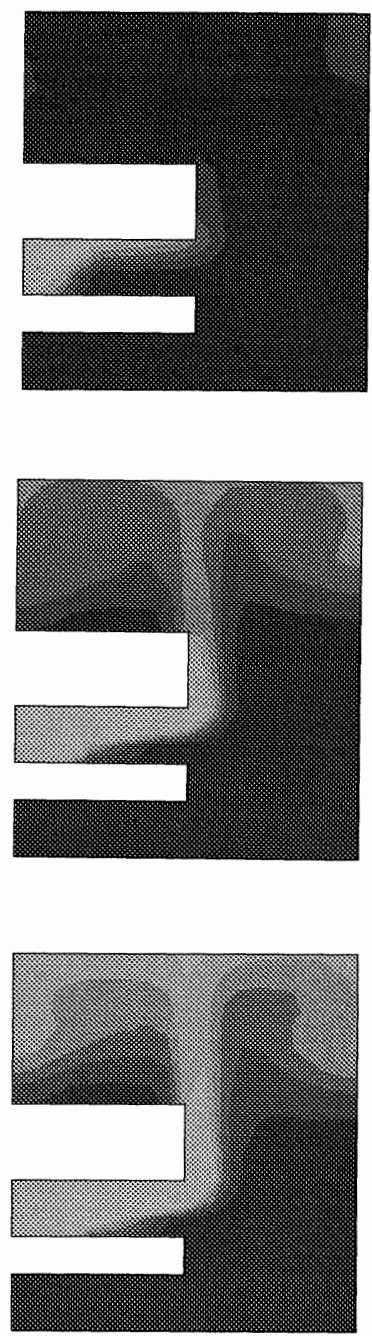
FIGURE 5 Mass fraction of soot at the tunnel exit:

top - 120s; middle - 240s; bottom - 360s. (Contour range I.E-5 to $5 E-5$.)
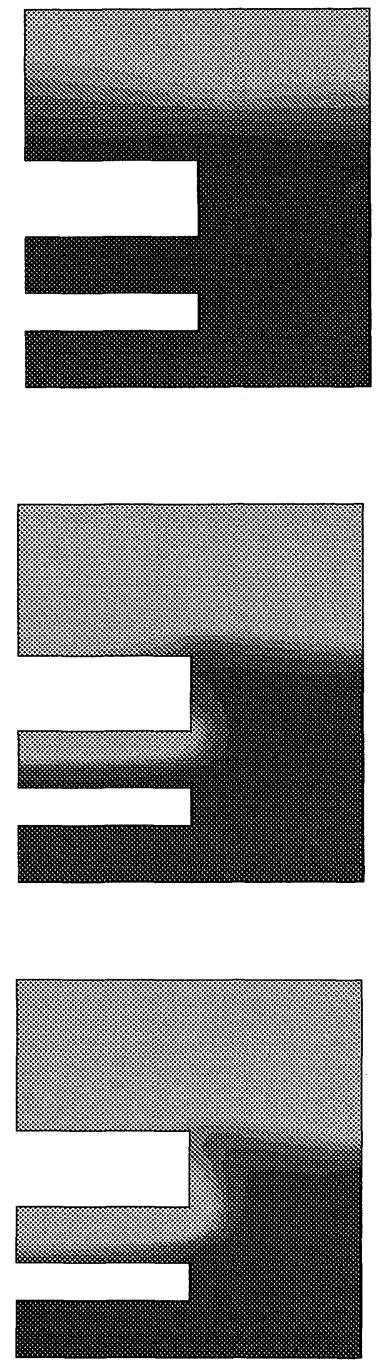

Figure 6 Temperature distribution from the $\mathrm{S}$ grade belt at 360 seconds. (Contour range 300 to $360 \mathrm{~K}$.)

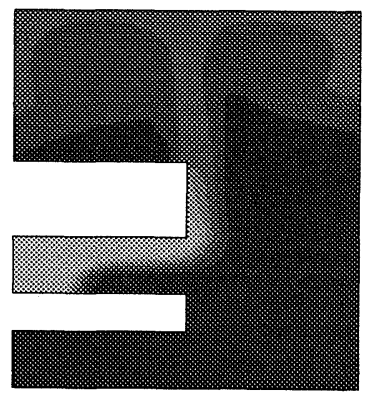


Figure 6, is compared with that shown in Figure 4 (bottom). At the exit of the tunnel the smoke layer is not as deep as for the A grade belt and at $600 \mathrm{~s}$, a person standing would not have their visibility or breathing impaired. The $5 \mathrm{E}-5$ soot contour corresponds to $30 \mathrm{ppm}$ carbon monoxide and $150 \mathrm{ppm}$ carbon dioxide, respectively.

The difficulty of escaping was also investigated by plotting profiles of the smoke mass fraction and the temperature along the tunnel. This plotting was carried out $2 \mathrm{~m}$ from the axis of the tunnel, which provides information at a distance of $0.7 \mathrm{~m}$ from the tunnel wall. A person trying to escape would most likely use the wall as a reference line and follow the path plotted. These showed there to be a hot layer at the top of the tunnel but the temperature at $2 \mathrm{~m}$ from the ground was close to ambient all the way out. A similar plot for the mass fraction of soot showed there to be a considerable amount of smoke in the vicinity of the fire but that further along the tunnel a person could escape by keeping close to the ground.

\section{The Effect of Tunnel Length}

An additional calculation was performed in order to investigate the effect of tunnel length. This calculation used a tunnel length of $100 \mathrm{~m}$, and 50 grid points in the direction of the tunnel. The grid in the region of the fire was unchanged but it was coarsened further down the tunnel to keep the calculation time manageable. The calculation was performed for the " $A$ " grade belt and assumed a fire of $0.5 \mathrm{MW}$ which was ramped up as $\mathrm{t}^{2}$ over $300 \mathrm{~s}$. The calculation was run for a total time of $600 \mathrm{~s}$.

At the fire itself the results were very similar to those discussed above. Further along the tunnel there was a greater concentration of smoke near the ground. However, the calculations suggest that the smoke concentration is not sufficiently high that a person would be unable to crawl out under the worst affected regions. This hypothesis was checked by plotting the temperature and smoke concentration along the tunnel, $0.7 \mathrm{~m}$ from the side wall. These showed that although there was smoke almost down to the floor in places, its concentration was less than about $15 \mathrm{E}-5$. At this level of concentration the visibility is about $6 \mathrm{~m}$, compared with $20 \mathrm{~m}$ for a concentration of 5E-5 [20]. The concentration of carbon monoxide would be less than $40 \mathrm{ppm}$.

\section{CONCLUSIONS}

The calculations presented in this paper have quantified the spread of smoke, heat, carbon monoxide and carbon dioxide within a mine tunnel using Cone Calorimeter data for several conveyor belt materials. The transport of heat and smoke from the fire has been determined using the Computational Fluid Dynamics model CFX4. The material produces a considerable amount of smoke, which the calculations show gets rapidly convected into the region above the conveyor. This smoke layer descends and eventually fills most of the region adjacent to the fire. Even after $600 \mathrm{~s}$ from the start of the fire the more dense region of the smoke layer at the end of the tunnel section studied is above the floor, showing that it would be possible for a person in the tunnel to escape by stooping or crawling. It should be noted that the calculations presented here do not allow for turbulent mixing induced by the various support structures which hold up the conveyor system. However, it is believed that they do give a good indication of the likely smoke spread rate and behaviour up to a distance of around $20 \mathrm{~m}$ from the fire. The calculations also show that the carbon monoxide levels are above the threshold exposure limits and tending towards lethal concentrations 
[22] above the conveyor belt. However, the levels where smoke visibility is greater than $6 \mathrm{~m}$, the concentrations are low enough to allow escape.

\section{ACKNOWLEDGEMENTS}

The authors wish to thank the WorkCover Authority of NSW for allowing them use of the Cone calorimeter, and Ms. Lynnae Fitch for her assistance in obtaining the data.

\section{REFERENCES}

1) NSW Coal Mining Act 1906 and subsequent amendments.

2) A.R. Green, R.W. Bilger, A Review of Flammability Test Methods for Evaluating the Fire Resistance of Materials Used Underground, LISC RR-C-1, 1985.

3) W.J. Koppe, Conveyor Design Guideline Safety Aspects, Engineering Safety Seminar, Dept. Mineral Resources, NSW State Government, May 1992, pp 1-28.

4) W.J. Koppe, Private Communication, 17th March 1995.

5) V. Babrauskas, "Development of a Cone Calorimeter: A Bench Scale Heat Release Apparatus Based on Oxygen Consumption", Report NBSIR 82-2611, National Bureau of Standards, Washington DC, US, 1982.

6) C Huggett, "Estimation of Rate of Heat release by Means of Oxygen Consumption Measurements, : Fire \& Materials, 4, 61-65, . (1980).

7) Fire and Safety Engineering, Technical Papers-Book 1, The Warren Centre for advanced engineering, University of Sydney, 1989.

8) V.B. Apte, A.R. Green, J.H. Kent, Pool Fire Plume Flow in a Large- Scale Wind Tunnel, Proc. 3rd Int Symp. Fire Safety Science, Edinburgh, 425-434, 1991.

9) D.F. Fletcher, J.H. Kent, V.B. Apte, A.R. Green, Numerical Simulations of smoke movement from a Pool Fire in a Ventilated Tunnel, Fire Safety Journal, 23, 305-325, 1995.

10) V.B. Apte, R.W. Bilger, A.R. Green, J.G. Quintiere, Wind-Aided Turbulent Flame Spread and Burning Over Large- Scale Horizontal PMMA Surfaces, Combustion \& Flame, 85, 169-184, (1991).

11) A.R. Green, V.B. Apte, R.W. Bilger, Flame Spread Along Horizontal Conveyor Systems, Proc. 23rd Int. Conf. Safety in Mines Research Institutes, Washington, 127135,1989

12) J.H. Kent, Turbulent Diffusion Flame Sooting - Relationship to Smoke-Point Tests, Combustion \& Flame, 67, 223-233, 1987.

13) CFX4 User Guide, AEA Technology, Harwell, Didcot, Oxon., UK., 1995 
14) S. Simcox, N.S. Wilkes, I.P. Jones, Computer Simulation of the Flows of Hot Gases from the Fire at King's Cross Underground Station, Fire Safety Journal, 18, 49-74, (1992).

15) K.A. Notarianni, W.D. Davis, The Use of Computer Models to Predict Temperature and Smoke Movement in High Bay Spaces, National Aeronautics and Space Administration Report: NISTIR 5304, 1993.

16) A. Askari, D.F. Fletcher, T.J. Lockett, Y.L. Sinai, C.P. Thompson, Fire Modelling for the Offshore Industry, Procs. Interflam'93, Interscience Communications Ltd, 375-384, (1993).

17) P. Chasse, Sensitivity Study of Different Modelling Techniques for the Computer Simulation of Tunnel Fires and Comparison with Experimental Measures, Proc. First CFDS International User Conference, Oxford, UK, 4-7 May, (1993).

18) Y.L. Sinai, M.P. Owens, Validation of CFD Modelling of Unconfined Pool Fires with Cross-Wind: Flame Geometry, Fire Safety Journal, 24, 1-34, (1995).

19) G. Cox, Combustion Fundamentals of Fire, Academic Press, (1995).

20) G.W. Mulholland, Smoke Production and Properties, Chapter 25, The SFPE handbook of Fire Protection Engineering, (1988).

21) Lewis: Sax's Dangerous Properties of Industrial Materials, Van Nostrand, New York, 1992 ISBN 0-442-01132-6 